ISSN 00156043

\title{
La economía civil en la perspectiva de la doctrina social de la Iglesia
}

\section{Stefano Zamagni'}

Resumen: Al aceptar la invitación de UNIJES para participar en este simposio, me propuse poner en relación mi enfoque actual de reflexión y trabajo con la doctrina social de la Iglesia (DSI). Para ello articularé la exposición en dos partes: una primera parte en la que mostrar las líneas maestras de la Economía civil, surgida de la misma matriz de pensamiento que la DSI. Este paradigma ofrece grandes posibilidades de investigación y realización desde una lógica económica acorde con el principio de fraternidad; en la segunda intentaré mostrar algunas claves éticas de la doctrina social de la lglesia, su articulación a partir de la idea de bien común frente a la de bien total y, para acabar, una propuesta de aplicación de esta lógica al flujo incesante de las res novae, incluyendo la configuración actual de los mercados.

Palabras clave: bien común, doctrina social, economía civil, fraternidad.

Fecha de recepción: 31 de enero de 2014.

The civil economy in the perspective of the social doctrine of the Church

Abstract: When I accepted the invitation from UNIJES to participate in this sympo-
L'économie civile dans la perspective de l'enseignement social de l'Église

Résumé: En acceptantl'invitation del'UNIJES à participer à ce colloque, j'ai décidé

' Universidad de Bolonia (Italia). 
sium, I decided to relate my current focus of reflection and work (which is civil economy) with the Social Doctrine of the Church. I have articulated my speech into two different parts: the first one shows the outlines of the civil economy; it emerges from the same root than the Social Doctrine of the Church. This paradigm offers great possibilities of implementation and research from an economical logic consistent with the principle of fraternity: In the second part, I try to show some ethical keys of the Social Doctrine of the Church and its articulation from the idea of common good versus the idea of total good. Finally, I offer a proposal for the application of this logic to the incessant flow of the res novae, including the current market configuration.

Key words: common good, social teaching, civil economy, brotherhood. de mettre en relation mon objectif actuel de réflexion et de travailler avec la doctrine sociale de l'église (DSI). Cette exposition est faite en deux parties: une première partie qui montrent les orientations générales de l'économie civile, issus de la même matrice de la pensée que la DSI. Ce paradigme offre un grand potentiel pour la recherche et réalisation conformément au principe de la logique économique de fraternité; dans la seconde, je vais essayer de montrer quelques clés d'éthiques à la doctrine sociale de l'église, son articulation de l'idée du bien commun contre le bien total et, enfin, une proposition de mise en œuvre de cette logique pour le flux incessant de les res novae, y compris la configuration actuelle des marchés.

Mots clé: bien commun, enseignement social, économie civile, fraternité.

Al aceptar la invitación de UNIJES para participar en este simposio, me propuse poner en relación mi enfoque actual de reflexión y trabajo con la doctrina social de la Iglesia (DSI, a partir de ahora). Para ello articularé la exposición en dos partes: una primera parte en la que mostrar las líneas maestras de la Economía civil, surgida de la misma matriz de pensamiento que la DSI. Este paradigma ofrece grandes posibilidades de investigación y realización desde una lógica económica acorde con el principio de fraternidad; en la segunda intentaré mostrar algunas claves éticas de la doctrina social de la Iglesia, su articulación a partir de la idea de bien común frente a la de bien total y, para acabar, una propuesta de aplicación de esta lógica al flujo incesante de las res novae, incluyendo la configuración actual de los mercados.

Un signo de los tiempos actuales -que merecería una lectura más atenta de la que está recibiendo- es la insistente reivindicación de la ética. Este fenómeno ha venido a sustituir aquella otra insistente llamada a la política, típica de los años 60 del siglo pasado, según la cual "todo era política". Sin embargo, como se puede constatar, la convergencia sobre el primado de la ética decae en el mismo momento en el que comenzamos a razonar sobre cuestiones éticas concretas, 
como ya había anticipado el filósofo A. Maclntyre en su célebre obra Tras la virtud (1982). Después de que el autor relacionara la pluralidad de teorías que caracterizaban el panorama ético contemporáneo, señalaba cómo el uso apodíctico de los principios éticos servía sólo para poner fin al propio diálogo ético. Es decir, aunque se pudiera constatar la convergencia sobre la primacía de la ética, esto no conduciría al consenso ético.

Se trata de una cuestión a la que el magisterio de Juan Pablo ll se refirió de modo casi ininterrumpido. En su discurso a las Naciones Unidas del 5 de octubre de 1995, el Papa insistió sobre la idea de que es posible entenderse sobre cuestiones de orden socio-político sobre una base común compartida, porque la ley moral universal escrita en el corazón del hombre es esa especie de gramática que sirve al mundo para afrontar la discusión sobre su propio futuro (Enseñanzas de Juan Pablo II, Vaticano, 1995, pág. 732). En otra alocución posterior, dirigida esta vez a los miembros de la Congregación para la Doctrina de la Fe, Juan Pablo II recordaba la idoneidad de la ley moral natural como instrumento de diálogo con todos. En este discurso afirmaba que si la ley moral no había asumido de facto esa función era por la difusión entre los creyentes de una moral de carácter fideísta y por tanto por la falta de un referente objetivo para las legislaciones, que habitualmente se basan tan solo en el consenso social.

\section{La Economía civil}

\section{I. La Economía civil como expresión del bien común}

¿Qué implicaciones de orden práctico derivan de la aceptación de la perspectiva de la ética del bien común? La primera tiene que ver con la relación entre Economía civil y crisis económico-financiera.

Estos últimos cinco años no han mostrado sólo la grave crisis del capitalismo financiero fundado sobre el endeudamiento (privado en Estados Unidos, público en la Europa mediterránea). También ha sido -y sigue siendo- un período muy importante para la Economía civil.

La crisis ha creado las pre-condiciones culturales idóneas para comprender la relevancia económica, social y ética de una visión de la economía y de las finanzas distinta y sostenible. La Economía civil es una tradición de pensamiento y de cultura civil que, sin renegar de la economía de mercado, invoca su antigua y originaria 
vocación de ser aliado del bien común, un lugar de libertad y de solidaridad, y de expresión de las capabilities de la persona. De esta grave crisis, que va mucho más allá de la dimensión exclusivamente económica, no saldremos eliminando (en caso de que fuera posible hacerlo) finanzas y mercados, sino sólo con unas finanzas y unos mercados civiles y civilizadores. Conviene recordar una de las lecciones de la tradición de la Economía civil: los mercados reales, a diferencia de los que aparecen en los libros de texto, no son lugares éticamente neutrales; o son civiles, o son inciviles, tertium non datur. Si las finanzas y los mercados no crean valor y valores, si no crean trabajo, si no respetan y cuidan del medio ambiente, son simplemente inciviles, destruyen la economía y la civilización, como seguimos viendo también en esta fase de la crisis. Estos últimos años, que han visto agudizarse la crisis que estalló en septiembre de 2008, han mostrado, con la fuerza de los hechos y con el dolor de la gente (no debemos olvidar que esta crisis se está jugando sobre la piel de las personas, de las más frágiles, sobre todo), que la economía de mercado sobrevivirá a esta crisis sólo si es capaz de avanzar más allá de este capitalismo individualista-financiero, y encaminarse hacia una Economía civil y civilizadora.

En segundo lugar, en estos años de crisis ha aumentado el número de actores de la Economía civil. Ésta tiene dos significados y acepciones principales: la que podemos escribir con " $E$ " mayúscula, es una tradición de pensamiento y una perspectiva sobre la economía, que lee toda la economía de un modo distinto al modo en que la lee la tradición del capitalismo estadounidense, aún dominante. Esta primera acepción no tiene que ver directamente con el Tercer Sector, y aún menos con el non-profit (concepto nacido en los Estados Unidos, que no capta la especificidad de la Economía civil).

Esta Economía civil, por tanto, se dirige a toda la economía y a la sociedad, ofrece un criterio de juicio y de acción para las decisiones del gobierno, de las multinacionales y de los consumidores (consumo crítico y responsable), y para las de los ahorradores.

También existe la economía civil con " $e$ " minúscula, que puede ser usada como sinónimo (aunque sin coincidir totalmente con ellas) de expresiones como economía social, privado social, economía motivada por ideales, y otras. Pero también esta segunda acepción "minúscula" de la economía civil tiene su especificidad y su originalidad, ya que incluye a sujetos y protagonistas que permanecen fuera de otras visiones y definiciones. Entre estos se encuentran sujetos tales como buena parte de los agentes de la cooperación tradicional o de la Economía de Comunión que por su forma jurídica o por tradición, no entrarían ni en el non-profit ni en ciertas definiciones de la economía social (las más anti-mercado). 
Los años de la crisis han visto crecer tanto la "versión mayúscula" como la "minúscula" de la Economía civil. Por una parte, ha crecido y se ha hecho más internacional la reflexión cultural de los estudiosos de la economía civil; pero también ha crecido el movimiento compuesto por quienes creen y trabajan para empresas comunitarias y solidarias, por quienes conciben el mercado como lugar en el que practicar las virtudes civiles, nacidas de un compromiso ético y espiritual.

\section{I.2. La raíz cristiana de la Economía civil}

La Economía civil, por tanto, es también y sobre todo una tradición de expresión de la cultura y del humanismo europeo, y de sus profundas raíces cristianas. Europa, como sabemos, ha dado vida a una versión propia de la economía de mercado, que nace del corazón de la christianitas medieval, y después del humanismo civil. Los monasterios primero y los grandes carismas mendicantes después, crearon las primeras categorías económicas y el primer léxico comercial de Europa, que posteriormente florecería con la modernidad en la Economía de mercado. Las primeras grandes ferias medievales serpenteaban a orillas de los grandes ríos europeos, y las abadías y monasterios fueron el centro de esta primera forma de comunidad económica europea, que fue grande y fecunda porque constituía una realidad más amplia que la mera economía.

Los monasterios fueron auténticas células del tronco del tejido europeo, al cual regeneraron pieza a pieza tras la caída del imperio romano. Aquellos monjes no sólo salvavan a Aristóteles, Séneca, Platón, Isaías o las cartas de Pablo, sino también cepas antiquísimas, técnicas de construcción y recuperación, de canalización y de irrigación del terreno, el patrimonio jurídico romano, las técnicas de acuñación de la moneda y antiguas costumbres comerciales.

Todo esto y mucho más fue el monacato europeo, en Occidente y también en Oriente; fue un inmenso vivero que no sólo conservó antiguas semillas, sino que incorporó nuevos injertos, dando vida a aquella extraordinaria primavera que fue y que es Europa. Las abadías y los monasterios salvaron la civilización de modo creativo, ya que fueron lugares donde se gestaron grandes innovaciones. Ellos representaron durante el medievo y, aunque con un peso diverso y menor, en la modernidad auténticos laboratorios vivos de los que tomaron vida formas de democracia (los abades eran elegidos en el seno de criterios de gobernanza de una cierta complejidad y articulación) y de relativa autonomía política (tanto de los emperadores como del papado y los obispos) y fueron muy importantes como paradigmas de democracia civil desarrollados en el interior de las ciudades europeas. 
No debemos olvidar que en aquellos monasterios se crearon las primeras formas de división del trabajo y de organizaciones racionales del tiempo y de los lugares. La visión litúrgica de la vida y de la jornada (jalonada por las diversas orae), la parcelación de responsabilidades y funciones (cada monje desarrollaba su función específica en el interior del cuerpo social), fueron las premisas culturales que dieron vida a aquel sistema de cooperación racional a gran escala y a aquella coralidad productiva que evolucionaría en las formas cooperativas de las fábricas, de las ferias (que se desarrollarían con frecuencia y no por casualidad junto a las abadías: por la necesidad de la fides en las empresas, ciertamente, pero también por la cultura cooperativa que emanaba de ellas), y también distritos industriales europeos (la práctica del coro, tanto en el canto como en la oración, fue también una experiencia cooperativa fundamental que no sólo está en el origen de la gran tradición musical europea-Guido d'Arezzo era un monje (ifraile?), obviamente-, sino también del ethos cooperativo de las empresas y del trabajo). Las primeras formas de pin factory organizadas sobre la base de la división racional del trabajo, de la que habla Smith en La riqueza de las naciones, maduraron en los molinos, en las cervecerías, en las bibliotecas y en los viñedos de los monasterios europeos, antes que en los arsenales de Venecia y de otras ciudades marineras italianas y europeas. Todo esto y mucho más se encuentra en las raíces de la Economía civil y de Europa, de sus instituciones, de sus sistemas de welfare, de sus mercados, que tienen diferencias específicas respecto a las versiones estadounidenses del mercado, fundado profundamente sobre una ética calvinista y su virtud característica, ética calvinista y virtudes individuales presentes también en Europa, pero junto a una ética católica con virtudes más comunitarias (que también cuando enferman -y la historia europea es también la historia de sus graves enfermedades sociales, políticas, económicas- mantienen como vocación virtudes civiles relacionales).

\section{Algunas claves éticas de la Doctrina social de la Iglesia}

\section{I. Reivindicación de la primacía de la ética}

Como he indicado al principio de este escrito, hoy uno de los signos de los tiempos es la constante reivindicación de la ética, aunque este consenso de difumine cuando queremos pasar de la simple afirmación de la primacía de la ética al consenso sobre su contenido y por tanto su alcance. Desde este punto de partida, el objetivo al que dirijo aquí mi atención es el de mostrar que la Doctrina social de la Iglesia, bajo una condición precisa, puede ofrecerse actualmente como una 
vía privilegiada para favorecer, a modo de puente, una convergencia entre las muchas aproximaciones a la cuestión ética tanto en el ámbito económico como en el socio-político. La condición precisa a la que hago referencia es que la DSI sea visualizada no como teoría moral ulterior respecto a las muchas ya disponibles en la literatura, sino como una gramática común a todas ellas, en tanto que se funda sobre un específico punto de vista: el cuidado del bien humano.

De hecho, mientras que las diferentes teorías éticas -tan de moda en la actualidadponen su mira en la búsqueda de reglas (como sucede con las distintas versiones de la doctrina positivista de la ley natural, según la cual la ética deriva del imperio de la ley), o en el tema de la acción (pensemos en las teorías utilitaristas y contractuales), la DSI acepta como su punto de Arquímedes la idea de estar con. La ética, antes incluso de ocuparse de establecer los principios y de sugerir reglas, es un hogar, una casa en la que nos hacemos cargo de nosotros mismos y de los demás; en una palabra, en la que nos hacemos cargo del bien humano.

La esencia de la ética del bien común, que es el proprium de la DSI, es que para poder comprender la identidad del actuar humano, es preciso situarse en la perspectiva de la persona que actúa (Veritatis Splendor, $n^{\circ} 78$ ), y no en la perspectiva neutra de una tercera persona (como hace el iusnaturalismo), ni de un espectador imparcial (como Adam Smith, entre los primeros, propuso en su día). Ya el Aquinate había observado que el bien moral, siendo una realidad práctica, es conocido primariamente no por quien lo practica, sino por aquél que sabe individuarlo $y$, consecuentemente, elegirlo con certeza siempre que es puesto en discusión.

\subsection{La ética del bien común frente a la lógica del bien total}

¿Qué significa acoger el punto de vista de la ética del bien común? Para responder, conviene tener presente que el tema central de la DSI, es decir, el fin al que ésta se orienta, es la construcción de un orden social no solamente justo, sino también fraterno. La actuación sociopolítica, de hecho, no puede ser entendida reductivamente como el conjunto de instituciones, reglas e instrumentos que sirven para asegurar la convivencia social, sino también y sobre todo, la vida en común. Ya Aristóteles había entendido la profunda diferencia entre la vida en común y la mera convivencia, que también es propia de los animales (sobre esto volveré posteriormente). Si la vida en común es el contexto en el que se realizan los planes de vida individuales, que son éticamente sensibles, entonces también ese contexto debe ser reconocido como provisto de una dimensión ética. De lo contrario, se incurriría en una flagrante contradicción pragmática. Es por esto que, como oportunamente 
escribe Viola, el empeño sociopolítico pertenece a la concepción cristiana de la vida humana, y que una crítica moral de la vida política deba ser considerada pertinente, y no meramente yuxtapuesta a la argumentación política.

¿Qué hay detrás de la expresión bien común? Un modo simple pero eficaz de entender el significado de esta expresión es ponerlo en confrontación con el concepto de bien total. Mientras que este último puede ser representado con la imagen de una suma, en la que los sumandos representan los bienes individuales (o de los grupos sociales de los que está compuesta la sociedad), el bien común es identificable con una multiplicación, cuyos factores representan el bien de los individuos o grupos. El sentido de la metáfora es claro: en una suma, aunque algunos de los sumandos resulten anulados, el total seguirá siendo positivo. Más aún, puede suceder que si el objetivo es el de maximizar el bien total (p.e., el PIB nacional), convenga anular el bien (o el bienestar) de algunos a condición de que el incremento de bienestar de otros aumente en una cantidad mayor. En la multiplicación sucede al contrario, ya que la anulación de un solo factor convierte en cero el producto.

Dicho de otro modo, la lógica del bien común no admite la posibilidad de sustitución (o trade-off): no se puede sacrificar el bien de nadie -sea cual sea su situación de vida o su configuración social- para mejorar el bien de ningún otro. Y ello por la razón fundamental de que cada miembro de la sociedad es siempre una persona humana. En cambio, según la lógica del bien total, el miembro es un mero individuo, es decir, un sujeto identificado con una particular función de utilidad, y las utilidades pueden ser sumadas porque no tienen rostro (es decir, identidad) ni historia. Como ya había aclarado Aristóteles, la vida en común entre los seres humanos es muy distinta de la mera comunidad de pastos propia de los animales. En la comunidad de pastos, cada animal come por su propia cuenta e intenta -si es capaz- sustraer comida a los otros. En la sociedad humana, al contrario, el bien de cada uno puede ser alcanzado sólo con el trabajo de todos. Es decir, el bien de cada uno no puede ser recibido (o sea, disfrutado) si no lo es también el de los demás.

¿Por qué las nociones de bien comúny bien total siguen siendo confundidas entre los académicos, generando numerosos equívocos y disputas estériles que no conducen a ninguna conclusión? La respuesta más convincente es que la cultura dominante en la actualidad está tan imbuida en el utilitarismo filosófico que, incluso los contextos que-al menos formalmente- le expresan aversión, terminan por contagiarse de sus condicionamientos prácticos. Es preciso tener presente que es con la ética utilitarista de J. Bentham (1789) con la que se afirma y se difunde la idea de que el objeto de la política es el bien total del pueblo, por lo que la organización del mercado 
(es decir, de la economía) y de las instituciones públicas debe configurarse de tal modo que no obstaculice la consecución de dicho objetivo.

Mientras la razón utilitarista ha quedado circunscrita al ámbito socioeconómico, hemos conseguido encontrar remedio para las incongruencias que ha generado -sobre todo en lo relativo a la distribución de la riqueza- . Después de todo, ahí reside el significado último del Estado del bienestar, cuyo fundamento filosófico es marcadamente hobbesiano: ya que la lógica del bien total no asegura de hecho que todos los ciudadanos puedan vivir de manera decente, y ya que las situaciones de pobreza prolongada o de acentuada desigualdad entre los grupos sociales son dañinas - por razones obvias- para maximizar el bien total, se confía al Estado la tarea de intervenir post-factum para compensar (en el sentido de resarcir) a aquellos que, por una u otra razón, han quedado demasiado atrás en la carrera del mercado. Sin embargo, en años recientes, el compromiso hobbesiano ha mostrado ser totalmente inadecuado cuando se ha intentado extender la lógica del bien común a la esfera de lo que $M$. Foucault ha llamado la biopolítica: se sacrifica un embrión humano para aventajar, es decir, para aumentar el bienestar de algunos individuos; se legaliza la eutanasia para que ésta ponga fin a la des-utilidad del sufriente y de quienes deben asistirlo; etc.

Pero aún existe otra consecuencia de la perniciosa confusión entre bien común y bien total que conviene señalar, y que implica directamente al mundo católico: la sinonimia de facto de las palabras caridad y solidaridad. Valgan algunos ejemplos:

En el Catecismo de la Iglesia Católica (1992), el término solidaridad es mencionado en 23 ocasiones. En cambio, en los textos emanados del Concilio Vaticano II, el término en cuestión es utilizado tan sólo en nueve ocasiones. Cabe observar que la constitución apostólica Gaudium et spes no emplea la expresión doctrina social para referirse a la DSI, sino más bien a la doctrina de societate. Esta mutación de términos ni siquiera habría sido notada de no ser por la intervención, pocos años después, de M. D. Chenu, con su influyente tesis según la cual la DSI sería una mera enseñanza social de la Iglesia que se limita a leer las res novae que constituyen puntos de convergencia para muchas personas y que explican de algún modo su esperanza (M.D. Chenu, La dottrina sociale della Chiesa. Origine e sviluppo, Queriniana, Brescia, 1977).

Esta tesis es como mínimo desconcertante, ya que con el justísimo objetivo de conjurar el riesgo de convertir a la DSI en una ideología, o directamente en un programa político, la vacía de hecho de su contenido de principios propios o de su 
función práctico-orientativa. La disputa sería afrontada en la encíclica Sollicitudo rei socialis (1987), donde Juan Pablo II escribe que la DSI

no es tampoco una ideología, sino la cuidadosa formulación del resultado de una atenta reflexión sobre las complejas realidades de la vida del hombre [...]. Su objetivo principal es interpretar esas realidades, examinando su conformidad o diferencia con lo que el Evangelio enseña acerca del hombre y su vocación terrena y, a la vez, trascendente, para orientar en consecuencia la conducta cristiana. Por tanto, no pertenece al ámbito de la ideología, sino al de la teología y especialmente de la teología moral ( $n^{\circ} 41$; la dos palabras en letra redonda, señaladas por del autor).

Pero aún hay más. En el $n^{\circ} 2850$ del Catecismo se lee que el vínculo que nos une en el Cuerpo de Cristo es la solidaridad, y no ya la caridad. Por otra parte, el sínodo de los obispos de octubre de 2005 en Roma ha producido, como conclusión de su trabajo sobre el tema La eucaristía: fuente y culmen de la vida y de la misión de la Iglesia, un Mensaje en el que el concepto de solidaridad es mencionado tres veces $\left(n^{\circ} 4,5\right.$ y 13) y el de caridad tan solo una $\left(n^{\circ} 20\right)$. A nadie puede ocultarse los riesgos que corre el mensaje cristiano cuando los términos caridad y solidaridad son entendidos como equivalentes $y$, por lo tanto, sustituibles.

Por este motivo conviene precisar atentamente las características propias de la noción de bien común, el cual no puede ser confundido ni con bien privado ni con bien público. En el bien común, la ventaja que cada uno obtiene por el hecho de formar parte de una comunidad no puede ser escindida de la ventaja que obtienen los demás. Dicho de otro modo, los intereses de cada uno se realizan junto a los intereses de los demás, y no contra ellos (como sucede en el bien privado) ni prescindiendo de ellos (como sucede con el bien público). En ese sentido, el término común se opone a propio del mismo modo que el término público se opone a privado. Por tanto, es común aquello que no es sólo propio, ni aquello que pertenece a todos indistintamente. Ningún pensador contemporáneo ha visto mejor esta distinción que H. Arendt. En su célebre Vida activa, Arendt escribe que público indica aquello que está a la luz, aquello que se ve, de lo cual se puede hablar y discutir: cualquier cosa que aparece en público puede ser vista y oída por todos (1994, pág. 37). Privado, al contrario, es aquello que resulta sustraído a la vista. Común, de otra parte, es el mundo mismo en cuanto que es común a todos y distinto del espacio que cada uno de nosotros ocupa privadamente (pág. 39). Como tal, lo común es el lugar de aquello que no es propio, es decir, el lugar de las relaciones interpersonales.

¿Cuál es, entonces, el "enemigo" del bien común? De una parte, el que se aprovecha de los demás (free rider), es decir, el que vive a costa de los otros. De otra parte, el que se comporta como un altruista puro, y que, por tanto, anula sus propios intereses 
para favorecer los de los demás. Ninguno de estos comportamientos alimenta el bien común, aunque sea por motivos y con consecuencias distintas. Ni el egoísmo puro ni el altruismo puro son capaces de hacer sostenible por sí solos un orden social humano. ¿Cuál es, entonces, el amigo del bien común? El comportamiento inspirado por el principio de reciprocidad, el cual suena así: te doy libremente algo de modo que tú también puedas devolver, según tus capacidades, a mí mismo o a algún otro. Esta formulación contrasta claramente con el principio de intercambio de equivalentes, cuya formulación podría ser ésta: te doy algo a condición de que tú me devuelvas algo de un valor equivalente. Por tanto, mientras que el principio de reciprocidad postula-como ya había indicado Aristóteles-la proporcionalidad, el principio de intercambio de equivalentes postula la equivalencia.

Ninguna sociedad humana puede perdurar y ser además fuente de felicidad, es decir, de realización plena de la persona, si todos dan (al modo altruista puro del filántropo) o si todos pretenden recibir (al modo del oportunista o del asistido crónico), ni siquiera si todas las relaciones intersubjetivas son reducidas al esquema del intercambio de equivalentes. La confirmación a nivel cultural y la traducción práctica a nivel político del principio de reciprocidad son la garantía segura de una convivencia armoniosa y viable. Ésta es la contribución específica -aunque no sea la única- que el pensamiento católico puede y debe ofrecer a la regeneración de la polis. No es difícil darse cuenta. La estructura originaria del principio de reciprocidad es ternaria: yo, tú, el otro; en cambio, la del principio de intercambio de equivalentes es binaria (en el contrato sólo existe un yo y un tú). Como recuerda P. Ricoeur, es la entrada del tercero en la relación intersubjetiva lo que crea y mantiene en vida la sociedad.

\subsection{La atención permanente a las res novae}

¿Qué implicaciones de orden práctico y de especial interés para la realidad actual se desprenden de la acogida del discurso del bien común? Diversas y sobre planos distintos. Antes de exponer alguna, conviene atesorar una importante lección de método. La ciencia social ha formulado un teorema (Teorema de Thomas) que podría ser formulado así: si los hombres definen como reales ciertas situaciones, serán reales en sus consecuencias. Dicho de otro modo, la incorrecta interpretación de un fenómeno favorece una definición errada de los problemas y provoca medidas inadecuadas, si no abiertamente contraproducentes. De ahí la necesidad de un discernimiento que se nutre de estudio continuo y de investigación rigurosa. Se trata de una recomendación que los católicos no pueden decir que hayan seguido y hecho propia. 
Pero esto es cierto a un nivel aún más general. Estoy pensando en el Concilio Vaticano II, que asume como interlocutor principal la representación del mundo marxista cuando, a mitad de los años 60, en el debate filosófico internacional, el pensamiento marxista se consideraba ya superado. $Y$ sin embargo, el propio Concilio, después de haber señalado que el género humano se halla en un período nuevo de su historia, caracterizado por cambios profundos y acelerados, que progresivamente se extienden al universo entero (Gaudium et spes $n^{\circ} 4$ ), invitaba a los creyentes a considerar como parte integrante del propio empeño en el orden temporal la lectura y la interpretación de las res novae de nuestro tiempo.

Si esa recomendación era válida entonces, en 1965, también hoy sigue siéndolo, y aún con mayor razón. Sirvan para mostrarlo algunas breves consideraciones: en 1965, las democracias del mundo eran 42 ; hoy son 88 . El $60 \%$ de la población mundial vivía en sistemas sociales caracterizados por la ausencia de economía de mercado; hoy ese dato se ha reducido a una cifra inferior al 1\%. Las llamadas "nuevas pobrezas" no existían aún, y los sistemas de welfare funcionaban con vigor en la mayoría de los países del Occidente avanzado; hoy son justamente las nuevas pobrezas asociadas a la propagación de las nuevas tecnologías de la información las que llevan a hablar de la urgencia de un nuevo welfare. En 1965, el fenómeno de la globalización aún no había comenzado a dar muestras de su existencia (sería preciso esperar a la primera cumbre del G-6 de Rambouillet (París), en noviembre de 1975, para conocer las medidas de privatización y de liberalización que desencadenarían posteriormente el proceso de la globalización); hoy ya se habla de la posibilidad de que las naciones celebren el "Día de la Interdependencia" más que el "Día de la Independencia".

Aún en 1965, el conflicto social era básicamente un conflicto de intereses (justamente, ese es el conflicto entre los que tienen y los que no tienen). Hoy han explotado, junto con los conflictos de intereses, los conflictos de identidad. En la agenda de los movimientos de matriz fundamentalista no encontramos ya la lucha por la igualdad, sino la lucha por la identidad. Esto ha propiciado una auténtica idolatría de la propia identidad, en connivencia con algunas religiones que se han situado al servicio de las políticas identitarias para ofrecerles legitimación, o incluso justificación. Bastan estos pocos datos de fondo para entender cuánto trabajo de revisión habría sido necesario hacer y no se ha hecho por parte del laicado católico. Con la perspicacia profética que lo caracterizaba, Juan Pablo II, más que cualquier otro, demostró con la Centesimus Annus (1991) haber captado el pulso de las res novae. Un detalle particular confirma esta observación; mientras que en 1891 León XIII identificaba como grave problema los abusos del capitalismo y las fantasías del socialismo (Rerum Novarum, $\mathrm{n}^{\circ} 11$ ), un siglo 
después Juan Pablo II denunciaba los abusos del socialismo y las ilusiones del capitalismo.

Aclarado esto, la primera implicación de lo que acabamos de decir tiene que ver con el llamado nuevo welfare. Como es evidente, el Estado social, en la segunda mitad del siglo XX, ha representado una institución orientada a la consecución de dos objetivos principales: por un lado, reducir la pobreza y la exclusión social, redistribuyendo el rédito y la riqueza (función de Robin Hood). Por otro lado, ofrecer servicios de seguridad social, favoreciendo un posicionamiento eficiente de los recursos en el tiempo (función de hucha). En la base del primer objetivo estaba el propósito de utilizar el poder político para compensar el orden del egoísmo con el orden de la igualdad, utilizando una expresión de John Dunn. Para el filósofo político inglés, mientras la economía de mercado capitalista constituye un formidable mecanismo para organizar el orden del egoísmo, no existe nada similar que permita organizar el orden de la igualdad (cómo hacer vivir a las personas juntas en sociedad sin que ninguno se sienta humillado, es decir, sin que nadie se perciba a sí mismo como irrelevante). Sin embargo, el intento de lograr este objetivo a través del poder político en forma de welfare State no ha producido los efectos deseados (e incluso, en algunos casos, la situación ha empeorado).

En la base del segundo objetivo se encuentra una justificación técnica bien precisa: las limitaciones de los mercados asegurativos privados, consecuencia del conocido problema de la asimetría informativa, que provoca la necesidad de adoptar sistemas asegurativos sociales gestionados por el Estado. El instrumento ideado para satisfacer esta necesidad ha sido, básicamente, el siguiente: los gobiernos utilizan el dividendo del crecimiento económico para mejorar la posición relativa de los que están peor situados sin empeorar la posición absoluta de los que están mejor. Sin embargo, todo un conjunto de circunstancias - derivadas de la globalización y la tercera revolución industrial (la provocada por las nuevas teconologías infotelemáticas)- ha provocado en los países occidentales avanzados a partir de los años 80 una ralentización del crecimiento potencial, y ha comenzando a redistribuir los resultados del crecimiento entre las diversas áreas del mundo. Estos nuevos condicionantes, de naturaleza externa respecto a los gobiernos nacionales, han terminado por dar aliento, en el curso de la última década, a lo que P. Donati ha llamado el complejo lib-lab, que ha identificado en los mecanismos redistributivos de la tributación y de los sistemas de seguridad social la causa de la ralentización del crecimiento potencial y, por consiguiente, una escasez de recursos para la acción social de los gobiernos. La posición lib-lab se basa en el siguiente esquema de pensamiento: el crecimiento económico provoca como subproducto inevitable la desigualdad (una idea, por otra parte, bastante antigua, y que J. Schumpeter 
expresó con la célebre metáfora de la distribución creadora: el capitalismo, mientras destruye, crea, y crea porque destruye); por tanto, no se debe evitar la aparición de desigualdades provocadas por el hecho de que se mejore la posición relativa de quien está bien y sin empeorar en valor absoluto (sino que posiblemente mejore) la posición de quien está peor.

Las consecuencias de este modo de entender el welfare están a la vista de todos. No sólo el viejo welfare State se muestra incapaz de afrontar las nuevas pobrezas, sino que se muestra igualmente impotente para atajar las desigualdades sociales, en continuo aumento en nuestras sociedades. Por ejemplo, y como muestran las investigaciones del CENSIS, Italia se ha convertido ya en un país caracterizado por una movilidad de calibre reducido: las personas situadas en los niveles más bajos de la escala social tienen hoy mayores dificultades que antes para acceder a niveles más altos. Esto evidencia la existencia de auténticas trampas de pobreza: quien cae en ellas -por razones varias, incluida la responsabilidad personal- difícilmente consigue salir. Actualmente, la persona ineficiente es empujada fuera de la ciudadanía, sin que se reconozca la proporcionalidad de recursos. Frente a esta situación, la DSI no puede permanecer muda ni inactiva. ¿̇Qué mensajes provienen de la perspectiva del discurso del bien común de cara al diseño de un nuevo welfare? El primero es el de superar las nociones ya obsoletas, sea de desigualdad de resultados (aproximación lab), sea de desigualdad de posiciones de partida (aproximación lib). Más bien se trata de encontrar el modo de declinar la noción de desigualdad de las capacidades (en el sentido de A. Sen) mediante intervenciones que busquen dar respuesta a las personas para que éstas mejoren su posición de vida. El segundo mensaje es el de superar el convencimiento equivocado en base al cual los derechos subjetivos naturales (a la vida, a la libertad, a la propiedad) y los derechos sociales de ciudadanía (tutelados por las distintas tipologías de servicios de welfare) sean incompatibles entre sí, y que para defender los segundos sea necesario sacrificar o limitar los primeros. Como sabemos bien, tal convencimiento ha sido el origen de disputas ideológicas ociosas y de marginación de importantes recursos productivos.

Finalmente, conviene hacer referencia a un tercer mensaje, que invoca directamente el principio de subsidiariedad. El nuevo welfare, que debe conservar una orientación universalista, debe dirigir los recursos públicos para financiar no ya -como sucede hoy- a los sujetos que ofrecen servicios de welfare, sino a los sujetos que los demandan. De hecho, la financiación directa por parte del Estado de las agencias de welfare puede alterar la naturaleza de sus servicios y elevar sus costes. Cuando es el Estado quien elige los servicios o las prestaciones para los ciudadanos, necesariamente debe imponer niveles de calidad regulados en atención 
al ciudadano medio. De ahí deriva, por una parte, la despersonalización en el modo de satisfacer las necesidades, lo cual genera descontento (recordemos que estamos hablando de servicios a la persona); y por otra parte, esto provoca una elevación de los costes y una bajada de la calidad, dado que se ofrece un servicio que, para algunos, es de calidad superior a la que demandan (es decir, superior a la que el ciudadano elegiría si fuese libre para ello) y para otros es de calidad inferior respecto a las exigencias reales. Pero, sobre todo, la financiación directa de parte del Estado tiende a cancelar o a modificar la identidad de los sujetos de la sociedad civil. Esto es debido a que el desembolso de fondos a estas entidades les obliga a seguir procedimientos de tipo burocrático-administrativo que tienden a anular la especificidad propia de cada sujeto, y de la cual depende, en última instancia, la creación de capital civil, y que constituye el recurso intangible que marca las posibilidades de progreso de una nación.

Para evitar dudas conviene precisar que si se quiere tomar en seria consideración el principio de subsidiariedad -como pretende la DSI-, no es suficiente que éste venga declinado en términos verticales y horizontales. Existe una tercera acepción de tal principio que tiene que ver con la reciprocidad. Se trata no sólo de afirmar, como ya plantea la declinación horizontal de la subsidiariedad, que no haga el Estado aquello que puede hacer la reciprocidad, sino también que no haga el contrato aquello que puede hacer la reciprocidad. De hecho, si no se reconoce esta tercera dimensión de la subsidiariedad, no tendremos ningún criterio para preferir a una cooperativa social o a una sociedad capitalista por acciones en la gestión de una guardería. Antonio Genovesi -y también Adam Smith- tenían bien claro este principio, aunque no utilizaran esta expresión. En cambio atribuían al amor y la amistad un puesto de primacía respecto al intercambio de mercado, sabiendo que, en las grandes empresas, donde existe división del trabajo, éste es necesario: debemos resignarnos a aceptar el intercambio de equivalentes, que en cualquier caso no ostenta la primacía en la convivencia civil. Para estos autores, el mercado -la "mano invisible"- interviene como ayuda, a modo de subsidio, pero no es alternativo a la práctica de la virtud civil.

\subsection{El papel del mercado}

Es oportuno hacer mención de una segunda implicación importante de la adquisición en el debate público de la categoría de bien común. Actualmente se están confrontando, y en algunos casos colisionando, dos visiones del modo de concebir cuál debe ser la relación entre la esfera económica (que podríamos llamar sintéticamente, usando una acepción amplia del término, el mercado) y la esfera de 
lo social (o de la solidaridad). De una parte están quienes ven en la extensión de los mercados y de la lógica de la eficiencia la solución a todos los males sociales; de otra están los que, en cambio, entienden el avance de los mercados como una desertificación de la sociedad, la cual debe, en consecuencia, combatirlo para protegerse. La primera versión considera a la empresa como un ente "a-social" (expresión donde el prefijo " $a$ " contiene un matiz fuertemente privativo); según esta concepción, referida a algunas tradiciones de la ideología liberal, lo social es distinto de la mecánica del mercado, que se presenta como una institución ética y socialmente neutral. Desde esta visión, al mercado se le pide únicamente que sea eficiente, que cree riqueza y que haga más grande el pastel. La solidaridad, en cambio, comenzaría allí donde termina el mercado, ofreciendo criterios para repartir el pastel (en la esfera política), o interviniendo en sectores de la sociedad no alcanzados por el mercado.

En las antípodas de esta visión encontramos otra aproximación, que considera a la empresa como esencialmente anti-social. Esta concepción, que tiene en la nómina de sus teóricos autores como K. Marx y K. Polanyi, y como expresión más visible en la actualidad algunas de las componentes del "pueblo de Seattle", se caracteriza por concebir el mercado como lugar de abuso y explotación del fuerte sobre el débil (Marx), y a la sociedad como amenazada por los mercados: el mercado avanza sobre la desertificación de la sociedad (Polanyi). De aquí su llamada a proteger a la sociedad del mercado (y de las empresas multinacionales, en particular), con el argumento de que las relaciones verdaderamente humanas (como la amistad, la confianza, el don, la reciprocidad no instrumental, el amor, etc.) son destruidas con el avance del área de los mercados. Esta visión, que ciertamente capta algunas de las dinámicas de los mercados reales, tiende a ver lo económico y el mercado como deshumanizadores per se, como mecanismos destructores del capital social indispensable para toda convivencia auténticamente humana, además de para todo crecimiento económico.

La visión de la relación mercado-sociedad típica de la DSI, y que hunde sus raíces en el pensamiento clásico y en particular en el humanismo civil italiano, se sitúa en cambio en una perspectiva radicalmente distinta respecto a las dos visiones dominantes en la actualidad. La idea central, y por ende la propuesta de la Economía Civil, ya que emerge de la DSI, es la de vivir la experiencia de la socialidad humana, de la reciprocidad y de la fraternidad en el interior de una vida económica normal, no al lado, ni antes, ni después. Para la DSI, otros principios distintos de los de aprovechamiento e intercambio de equivalentes pueden encontrar lugar dentro de la actividad económica. De ese modo se supera la primera visión, que ve lo económico (los mercados) como lugar éticamente neutral basado únicamente 
en el principio de intercambio de equivalentes, ya que es el momento económico mismo quien, en función de la presencia o ausencia de estos otros principios, deviene civil o incivil.

Pero también supera la otra concepción mencionada, que entiende el don y la reciprocidad como una prerrogativa de otros momentos o esferas de la vida civil, visión ésta aún radicada en no pocas expresiones del Tercer Sector, que tampoco es sostenible actualmente al menos por dos razones:

a) En los mercados globalizados, la lógica de los dos tiempos (primero las empresas producen y después el Estado se ocupa de lo social) sobre la cual se funda la relación entre economía y sociedad (por ejemplo en el caso del welfare State) ya no funciona, porque ha dejado de ser cierto el elemento base de esta visión: el nexo estrecho entre riqueza y territorio, sobre el cual se pensó todo el sistema social en Occidente, y en Europa de modo particular. Actualmente, este mecanismo se ha roto a consecuencia de la globalización de los mercados. A la empresa se le pide que sea social en su actividad económica normal, y cada vez más personas advierten hoy esa exigencia, de modo que se comienza a hablar de balance social, de RSC, etc.

b) El efecto desplazamiento. Si el mercado y, más en general, la economía se convierten en mero lugar de intercambio instrumental, se incurre en una de las paradojas más preocupantes de la actualidad: la moneda mala desplaza a la buena. Se trata de una de las más antiguas leyes económicas; aunque originariamente se aplicaba al flujo monetario, este mecanismo ofrece una aplicabilidad más amplia. Por ejemplo, esta ley actúa siempre que las motivaciones intrínsecas (como la gratuidad) se confrontan con motivaciones extrínsecas (como la ganancia monetaria): las malas desplazan a las buenas. El intercambio basado sólo sobre los precios y el contrato instrumental desplaza otras formas de relación humana: si me pagan por sonreír, cada vez sonreiré menos gratis; como podemos constatar en nuestras familias, si al niño se le da una paga por cortar la hierba, dejará de colaborar gratis en casa. Del mismo modo el mercado, si se basa sólo en estos principios, erosiona las condiciones de su misma existencia, que son la confianza y la propensión a cooperar.

Nuestras sociedades tienen necesidad de tres principios autónomos para poderse desarrollar de modo armónico y ser, en consecuencia, capaces de proyectarse hacia el futuro: el intercambio de equivalentes de valor (que sucede mediante el contrato), la redistribución de la riqueza (a través del sistema fiscal) y la reciprocidad (a través de las obras que testimonian la fraternidad con los hechos). Todas 
las sociedades conocen esta estructura triádica; en algunas sociedades puede no existir el mercado, pero ciertamente existen formas de redistrubción de la riqueza $y$, sobre todo, existe el don como actividad simbólica que refuerza el sentido de pertenencia a la comunidad.

¿Qué sucede cuando uno de los tres principios se reduce o anula? Si se elimina el don como reciprocidad, tendremos el sistema económico del welfare State de la posguerra de tipo inglés (Beveridge y Keynes). El centro de este sistema es el Estado benevolente; es el mercado quien produce con eficiencia la riqueza que el Estado redistribuye según criterios de equidad. Si se elimina el principio de redistribución, obtenemos el modelo de capitalismo filantrópico (o el compasionate conservatorism). El mercado es la palanca del sistema, y debe ser dejado libre para actuar sin obstáculos (se trata del llamado neoliberalismo). De este modo, el mercado produce riqueza, y los ricos son caritativos con los pobres, utilizando para ello a la sociedad civil (que, en consecuencia, resulta deformada) y a sus organizaciones (entidades de caridad y fundaciones).

Finalmente, la eliminación del principio de intercambio de equivalentes produce los colectivismos y los comunitarismos de ayer y de hoy, en los que se menoscaba la lógica del contrato (a costa de generar ineficiencias y residuos). La historia hasta ahora nos ha enseñado que sólo pequeñas comunidad consiguen desarrollarse sin este principio.

La globalización está ampliando de modo formidable el área de aplicación del contrato (tanto que, a menudo, el término globalización se ha convertido en sinónimo de mercados globlales) y, como consecuencia a menudo no pretendida, tiende a desplazar el área de acción de la redistribución y del don. Una aldea global que no se construya sobre estos tres principios no puede sobrevivir. El mismo mercado, para poder funcionar, necesita también de cierta dosis de gratuidad, que no consigue producir y replicar por sí en cantidad y calidad suficientes (no existe, de hecho, el mercado de la gratuidad).

La idea de actividad económica que nace de una visión semejante es la de un pueblo con más dimensiones: no sólo la sociedad civil se rige sobre la armonía de los tres principios, sino que la misma actividad económica no puede ser regulada exclusivamente por el principio de intercambio de equivalentes, ya que también en ella los tres principios deben ser activados, aunque sea en formas y proporciones diversas. Así, además de la empresa multinacional de tipo capitalista, encontramos también el negocio artesano, la cooperativa, la empresa social, las empresas de la"economía de comunión", realidades que, con su propia identidad, insertan 
dentro del mercado la reciprocidad no instrumental. Con su operativa cotidiana, ellas reivindican la posibilidad de un mercado de más dimensiones, no sólo como un lugar donde practicar la eficiencia, sino también la socialidad y, sobre todo, la reciprocidad.

\section{A modo de conclusión}

La tradición económica europea ha sido civil y civilizadora porque ha sido también una aventura espiritual. A Europa le falta hoy espíritu. Cuando, después de la segunda guerra mundial, nace la primera comunidad europea, la tragedia y el enorme dolor que habían precedido y acompañado a las dos guerras mundiales crearon las pre-condiciones ideales y espirituales para imaginary probar a realizar una tierra común de paz y prosperidad. Aquel gran proyecto europeo hoy se está alejando cada vez más de nuestro horizonte. Y para entender el motivo de esto debemos realizar el ejercicio, actualmente muy arduo, de liberarnos de las crónicas cotidianas y de la lógica del corto plazo para regresar al origen, para entender hoy nuestra naturaleza, vocación y destino. Europa, ya lo hemos mencionado, ha sido construida sobre los mercaderes y los monjes, y la han construido juntos. Los mercaderes, las grandes ferias, los intercambios, los tratados comerciales no habrían propiciado durante el medievo ninguna idea de Europa sin la acción conjunta, complementaria y co-existencial del monacato, y por tanto de Francisco y Domingo, y de tantos otros carismas. El cristianismo y sus carismas (que han heredado y reelaborado una parte de la cultura clásica y hebrea) han aportado ese aliento vital que ha generado y nutrido a Europa, incluyendo su economía de mercado, su sistema de welfare y su banca.

Con la modernidad, a este espíritu cristiano originario se añaden, también como germinaciones parciales, otras tradiciones ideales, que han continuado nutriendo y desarrollando Europa y su proyecto civilizatorio. Cuando en la posguerra llegamos al nuevo proyecto europeo, sus raíces eran ya muy profundas: la cristiana, la socialista y la liberal. Este espíritu triple y único de la economía europea ha sido capaz de alimentarla y vivificarla, y de hacerle alcanzar resultados extraordinarios. La Europa de hoy está en crisis no sólo por falta de una política fiscal común - por la deuda pública, sino sobre todo porque han sido menoscavadas estas tradiciones ideales que alimentaron durante siglos su espíritu. Tradiciones que aún permanecen vivas en el subsuelo, aunque con una vitalidad distinta, ya que las aguas subterráneas han perdido el contacto con los canales y los acueductos, y no refrescan ya la tierra ni a sus habitantes. Su espíritu orginal es ahora más 
tenue, y tampoco se ven otros "espíritus" en el horizonte capaces de desempeñar la misma función vital y vivificante.

Pero, como enseñó hace cien años Max Weber y actualmente Luc Boltanski, también una economía de mercado moderna y posmoderna tiene una necesidad esencial de espíritu para poder vivir y crecer. El espíritu, como recuerda la cultura bíblica, es el aliento vital, lo que hace vivir y lo que indica que aún estamos vivos. Por este motivo, cuando una cultura pierde su espíritu, se interrumpe también su desarrollo civil y económico. La carestía de espíritu es hoy la primera forma de misera que está bloqueando a Europa, apagando en sus ciudadanos el sueño y la idea misma de Europa. Hoy faltan en Europa sobre todo nuevos monjes y nuevos monasterios; falta orare para recrear también las precondiciones del laborare. Y el vacío provocado por la ausencia de monjes y espíritu ha sido colmado en el alma de las personas y de los pueblos (que hoy son, no menos que ayer, animales espirituales) por el consumismo, en el que las mercaderías toman el lugar de los bienes relacionales. No habríamos salido de la época de crisis que siguió a la caída del imperio romano sin el monacato, que transformó aquella gran herida en una bendicion. La Europa actual no saldrá reforzada de esta época de crisis sin una nueva estación espiritual, si no es capaz de encontrar -de reencontrar-su espíritu, que antaño la fundó y que hoy puede refundarla: sin embargo, en nuestra época los bárbaros no esperan al otro lado de las fronteras, sino que llevan gobernándonos hace algún tiempo. Y nuestra falta de conciencia de ello constituye parte de nuestra difícil situación. No estamos esperando a Godot, sino a otro, sin duda muy diferente, a San Benito (A. McIntyre (2004), Tras la virtud, Barcelona, Crítica, pág. 322). 